\title{
Persepsi Statement Takers Terhadap Pengungkapan Kebenaran Konflik Aceh
}

\section{Statement Takers Perception of Truth Disclosure of Aceh Conflict}

\author{
Nailur Rahmah ${ }^{1}$, Haiyun Nisa ${ }^{2}$, Mirza $^{3}$, Zaujatul Amna ${ }^{4}$ \\ Fakultas Kedokteran, Universitas Syah Kuala, Indonesia \\ 1 nailurrahmah.nayl@gmail.com*; 2 haiyunnisa@unsyiah.ac.id , 3 mrz.tc81psi@gmail.com , \\ 4 amnazaujatul@unsyiah.ac.id \\ * Penulis Koresponden
}

\begin{abstract}
Abstrak
Konflik Aceh menimbulkan korban sebanyak 30.000 jiwa. Konflik ini berakhir damai dengan ditandatanganinya Memorandum of Understanding (MoU) di Helsinki dengan salah satu mandatnya ialah mewujudkan keadilan transisi bagi penyintas konflik yang diwujudkan melalui pengungkapan kebenaran konflik Aceh. Pengungkapan kebenaran dilaksanakan oleh statement takers yang turun langsung ke lapangan untuk menemui penyintas konflik, namun hal ini beresiko bagi statement takers untuk mengalami dampak psikologis. Metode yang digunakan pada penelitian ini adalah kualitatif melalui pendekatan eksploratif. Responden penelitian berjumlah empat orang statement takers yang terlibat dalam pengungkapan kebenaran konflik aceh. Teknik pemilihan sampel menggunakan purposive sampling, serta pengumpulan data melalui wawancara. Hasil penelitian menunjukkan bahwa statement takers mengalami reaksi emosional, terbebani secara moral, serta mengalami dampak fisik dan psikologis. Namun, pengungkapan kebenaran dinilai tepat karena sesuai dengan nilai moral dan budaya masyarakat Aceh. Kesimpulan penelitian ialah pengungkapan kebenaran konflik menjadi tindakan preventif agar konflik tidak terjadi lagi, sehingga pengungkapan kebenaran tetap dilaksanakan demi mewujudkan keadilan transisi dan tetap memerhatikan dampak negatif yang ditimbulkan.
\end{abstract}

Kata Kunci: Persepsi; Pengungkapan kebenaran; Konflik

\begin{abstract}
The Aceh conflict caused victim reach 30,000 lives. This conflict ended peacefully with the signing of a MoU in Helsinki with one of its mandates is to establish transitional justice for survivors of conflict which was conducted through the truthful disclosure of Aceh conflict. Disclosure of truth is carried out by statement takers who directly meet conflict survivors, but this process has a risk to psychological effects. The method used in this research is qualitative through an exploratory approach. Research respondents are four statement takers who were involved in disclosing the truth. Sampling method for this research is purposive sampling, and collecting research data using interviews. The results showed that the statement takers experienced emotional reactions, morally burdened, physical effects, and psychological effects. However, disclosure of the truth is considered appropriate because it is in accordance with the moral and cultural values of the Aceh people. The conclusion of the research is that the disclosure of the truth of the conflict becomes a preventive measure so that the conflict does not happen again, so that the disclosure of the truth must be carried out in order to realize transitional justice and continue to pay attention to the negative impacts
\end{abstract}

Keywords: Perception; Disclosure of the truth of conflict; Statement Takers

1. Pendahuluan

Konflik di Aceh mulai terjadi ketika pendeklarasian GAM (Gerakan Aceh Merdeka) tanggal 4 Desember 1976 oleh
Teungku Muhammad Hasan Tiro, tahun 1980-an situasi Aceh semakin bergejolak karena diterapkannya Operasi Jaring Merah (OJM) di Aceh sebagai bentuk kebijakan 
operasi militer untuk melawan pihak Tentara Negara Indonesia (TNI) (Hamid, 2019). Adapun puncak kekerasan dan pelanggaran HAM berat akibat konflik bersenjata terjadi pada tahun 1989 yang mengakibatkan korban jiwa sejumlah 10.000 hingga 30.000 jiwa dari pihak sipil (British Broadcasting Corporation [BBC], 2013).

Penandatanganan nota kesepakatan damai paska konflik Aceh dikenal dengan Memorendum of Understanding (MoU) Helsinki yang dilaksanakan pada tanggal 15 Agustus 2005 (Hamid, 2019). Seiring dengan berakhirnya konflik tersebut maka terbentuklah Komisi Kebenaran dan Rekonsiliasi Aceh (selanjutnya disingkat dengan KKRA) sebagai amanah perjanjian damai yang tertuang dalam MoU Helsinki (CNN Indonesia, 2017). KKRA merupakan lembaga non yudisial yang terdepan dalam proses penyelidikan kasus-kasus pelanggaran HAM berat masa lalu serta mewujudkan keadilan transisional (Hamid, 2019). Keadilan transisional merupakan upaya penyelesaian masalah yang berkaitan dengan pelanggaran HAM berat masa lalu, salah satunya ialah pengungkapan kebenaran (Mutua, 2015).

Pengungkapan kebenaran dilakukan oleh statement takers yang bertugas di lapangan untuk mengambil pernyataan dan bukti lainnya dari penyintas konflik maupun kerabat dari korban konflik (Akbar, 2017). Komisioner KKRA menyatakan bahwa statement takers mendapatkan hak berupa jaminan perlindungan saat bekerja di lapangan untuk mengambil data penyintas konflik (Wawancara personal, 25 Maret 2019, MY/47 tahun). Pelaksanaan pengungkapan kebenaran konflik Aceh ialah berupa proses pengambilan pernyataan yang dilakukan oleh statement takers serta Rapat Dengar Kesaksian (RDK) yang dilakukan secara terbuka (KKR, 2019). KKRA dalam rentang waktu 2017 hingga 2019 telah berhasil mengumpulkan pernyataan lebih dari 3.040 penyintas konflik Aceh (Zairi, 2019).

Pelaksanaan pengungkapan kebenaran memiliki dampak positif secara psikososial. Salah satunya ialah sebagai sarana pemulihan secara psikologis bagi penyintas melalui penemuan fakta-fakta terkait kekerasan HAM yang belum terungkap (Minow, 1998). Leebaw (2003) juga menambahkan bahwa pengungkapan kebenaran bertujuan untuk pelestarian ingatan serta berperan sebagai tindakan preventif agar konflik dan kekerasan HAM serupa tidak terulang kembali. Lebih lanjut, Tepperman (2002) menyampaikan bahwa pengungkapan kebenaran merupakan sarana bagi pelaku pelanggaran HAM dan tindakan kekerasan untuk mengakui dan mengungkapkan penyesalan serta memberikan jaminan ketidakberulangan atas kejadian yang pernah dilakukan.

Adapun dampak negatif secara psikososial dialami oleh statement takers, berupa mimpi buruk dan penurunan hasrat seksual terutama bagi statement takers yang terlibat dalam kasus-kasus kekerasan seksual (Mail \& Guardian, 1997). Statement takers juga mengalami permasalahan kesehatan fisik, paranoia, ketidakmampuan mengontrol emosi, peningkatan kecemasan, peningkatan agresivitas, bahkan mengalami gangguan penyalahgunaan zat terlarang (Lorey \& Beezey, 2002). Oleh karena itu, statement takers menghadapi tantangan emosional dalam menghadapi kasus pelanggaran HAM berat sehingga harus merespon situasi tersebut dengan gejala stres pasca trauma dan memengaruhi kehidupan sehari-hari, bahkan memengaruhi performansi dalam bekerja (Mail \& Guardian, 1997). Peneliti melakukan studi pendahuluan terhadap masyarakat untuk mengetahui urgensi pelaksanaan pengungkapan kebenaran dari perspektif masyarakat. Berikut merupakan hasil wawancara:

"Pengungkapan kebenaran membantu kita tahu siapa yang salah, siapa yang dirugikan, dan juga bisa mendidik publik mengenai dampak konflik, kemudian penyintas pun lebih diperhatikan haknya" (Wawancara personal, 13 Desember 2018, E0/25 Tahun).

Wawancara awal yang dilakukan
menunjukkan bahwa pengungkapan
kebenaran merupakan suatu bentuk
alternatif solusi terhadap permasalahan HAM
berat yang faktanya belum diketahui. Namun
disisi lain, statement takers selaku petugas
yang secara langsung ikut serta dalam
pengungkapan kebenaran juga mengalami
dampak negatif secara psikologis yang dapat
mengganggu kehidupan sehari-hari serta


memengaruhi performansi dalam bekerja. Harapan masyarakat dan kenyataan statement takers di lapangan mengenai pelaksanaan pengungkapan kebenaran yang kontradiktif membutuhkan adanya kejelasan dan rekomendasi yang berguna untuk memaksimalkan pelaksanaan pengungkapan kebenaran. Oleh karena itu, penelitian ini bertujuan untuk mengetahui bagaimana persepsi statement takers terhadap pengungkapan kebenaran konflik Aceh.

Persepsi-Allport (1955) menyatakan bahwa persepsi merupakan proses kognitif individu yang dipengaruhi oleh pengalaman, cakrawala, dan pengetahuan. Serangkaian proses sensoris yang dimulai dari pengenalan stimulus akan diterjemahkan menjadi persepsi, dan seterusnya akan diimplementasikan dalam bentuk tindakan (Goldstein, 2013). Menurut Allport (1955) persepsi merupakan suatu interelasi antar tiga aspek, yaitu aspek kognitif, aspek afektif, dan aspek konatif.

Pengungkapan Kebenaran KonflikMenurut Hayner (2011) pengungkapan kebenaran konflik merupakan proses pencatatan dan pendokumentasian pelanggaran HAM yang terjadi pada masa konflik untuk kemudian diketahui dan dibuktikan kebenarannya. Selanjutnya, hasil dari pengungkapan kebenaran konflik dapat dijadikan sebagai landasan untuk merekomendasikan penuntutan terhadap pelaku pelanggaran HAM, memenuhi kebutuhan reparasi penyintas konflik, serta mewujudkan penyembuhan psikologis dan rekonsiliasi (Hayner, 2011).

Statement Takers-Statement takers dapat didefinisikan sebagai seseorang yang bertugas menyusun kronologi peristiwa berdasarkan informasi yang didapatkan dari pemberi pernyataan dengan cara menerima pengaduan dari penyintas, saksi, maupun ahli waris korban melalui proses verifikasi dan prosedur yang relatif kompleks (Farid \& Simarmata, 2004).

\section{Metode}

Penelitian ini menggunakan pendekatan kualitatif dengan jenis penelitian eksploratif untuk mengetahui secara lebih mendalam tentang persepsi statement takers terhadap pengungkapan kebenaran yang menimbulkan dampak psikososial terutama bagi statement takers maupun bagi penyintas konflik.

Responden penelitian berjumlah empat orang ditentukan dengan menggunakan teknik purposive sampling dengan karakteristik berupa statement takers pengungkapan kebenaran konflik Aceh yang berasal dari Komisi Kebenaran dan Rekonsiliasi Aceh (KKRA), Lembaga Bantuan Hukum (LBH) Aceh, dan Komisi untuk Orang Hilang dan Kekerasan (KontraS) Aceh

Prosedur penelitian terdiri dari dua tahapan. Pertama, tahap pra-lapangan, peneliti mengumpulkan referensi terkait persepsi serta melakukan studi pendahuluan (preliminary research) yang mendukung penelitian, merumuskan panduan wawancara, melakukan expert review, menyiapkan informed consent, dan mencari responden penelitian. Kedua, tahap pekerjaan lapangan, peneliti menemui calon responden, menjelaskan tujuan penelitian, mengonfirmasi kesediaan responden untuk berpartisipasi dalam penelitian dengan mengisi informed consent, melaksanakan wawancara, melakukan pemeriksaan kelengkapan data, dan analisis data.

Data yang didapatkan dianalisis menggunakan model interaktif yang mengacu pada teori Miles, Huberman, dan Saldana (2014). Model interaktif dilakukan melalui proses analisis data yaitu dengan mereduksi data, melakukan penyajian data, dan penarikan kesimpulan atau verifikasi untuk mengetahui dinamika persepsi statement takers terhadap pengungkapan kebenaran konflik Aceh.

\section{Hasil dan Pembahasan}

Analisis data dilakukan berdasarkan pengelompokan data yang mengacu pada aspek-aspek persepsi dengan memberikan kode sebagai berikut: Responden satu (AW), responden dua (AD), responden tiga (SFFR), dan responden empat $(\mathrm{FH})$.

Seluruh responden penelitian mengetahui tujuan dari pelaksanaan pengungkapan kebenaran konflik Aceh yaitu untuk mencapai keadilan transisi, membangun perdamaian berkelanjutan, serta sebagai langkah preventif agar konflik tidak kembali terjadi di Aceh. Responden SFFR menyampaikan bahwa pengungkapan kebenaran konflik Aceh sebagai sebuah usaha untuk mencapai keadilan transisi. 
Selain itu, responden AW juga menyampaikan bahwa pengungkapan kebenaran penting dilakukan karena menjadi langkah awal untuk menuntaskan hak-hak sipil dalam bidang sosial dan ekonomi.

Hal tersebut sesuai dengan penelitian yang dilakukan oleh Papi (2015) yang menyatakan bahwa keadilan transisi merupakan langkah yang tepat untuk membangun perdamaian dan membantu menyelesaikan permasalahan yang ditinggalkan akibat konflik, salah satunya ialah sebagai langkah awal perbaikan hakhak sipil baik dalam bidang sosial maupun ekonomi. Adapun mekanisme keadilan transisi yang dapat digunakan cukup beragam, salah satunya ialah pengungkapan kebenaran (Millar, 2015). Hanya saja, responden AW menyampaikan bahwa sebagian besar penyintas konflik menyikapi pengungkapan kebenaran dengan apatis dan pesimis karena kurangnya sosialisasi sehingga berdampak pada keberhasilan pelaksanaan pengungkapan kebenaran. Sebagaimana penelitian yang dilakukan oleh Antic-Stauber (2017) bahwa sosialisasi pengungkapan kebenaran penting dilakukan agar dapat terlaksana dengan baik karena keberhasilan pengungkapan kebenaran membutuhkan waktu yang kompleks.

Seluruh responden menyampaikan bahwa pengungkapan kebenaran konflik dilaksanakan berdasarkan landasan Qanun Nomor 17 tahun 2013 mengenai KKRA yang disahkan oleh Pemerintah Aceh sebagai hasil perjuangan dari komunitas lokal. Appleby dan Davis (2018) menyampaikan bahwa Afrika Selatan juga merupakan wilayah yang melaksanakan pengungkapan kebenaran atas perjuangan komunitas lokal. Lokalitas menjadi kunci bagi kesuksesan pelaksanaan pengungkapan kebenaran Afrika Selatan karena masyarakat tidak percaya terhadap kegiatan sosial yang dilakukan oleh negara, karena biasanya kegiatan sosial yang dilakukan oleh negara tidak terlaksana dengan baik, bersifat represif, dan hanya memperkuat hegemoni kolonial (Appleby \& Davis, 2018).

Keseluruhan responden mengetahui bahwa pelaksana pengungkapan kebenaran ialah Komisi Kebenaran dan Rekonsiliasi Aceh (KKRA), serta peran dan tugas yang harus dijalankan oleh komisi tersebut. Salah satunya ialah tugas statement takers untuk mengambil pernyataan secara langsung dari penyintas konflik. Pekerjaan tersebut sangat menantang dan membutuhkan adanya jaminan keamanan dan keselamatan bagi statement takers dan penyintas konflik untuk memastikan kesejahteraan psikososial keduanya (Salih \& Samarasinghe, 2017). Sesuai dengan responden AW dan SFFR yang menyebutkan bahwa tantangan yang dihadapi oleh KKRA dalam menjalankan tugasnya saat ini ialah tidak adanya jaminan keamanan dan keselamatan bagi statement takers dan penyintas konflik Aceh.

Pengungkapan kebenaran konflik bukanlah merupakan kegiatan yang berorientasi pada pemberian bantuan. Namun, sebagaimana yang disampaikan oleh responden SFFR bahwa sebagian besar dari tokoh, penyintas konflik, bahkan masyarakat Aceh memiliki pemahaman bahwa pengungkapan kebenaran merupakan kegiatan yang berorientasi pada pemberian bantuan, sehingga mayoritas masyarakat menaruh harapan yang besar pada KKRA. Hal tersebut sejalan dengan penelitian yang dilakukan oleh Millar (2015) yang mana pengungkapan kebenaran dipahami oleh penyintas sebagai kegiatan yang berorientasi pada pemberian bantuan, tidak hanya itu, penyintas konflik juga memiliki ekspektasi yang besar terhadap KKR sedangkan tugas KKR sebenarnya hanya sebagai pelaksana pengungkapan kebenaran dan berusaha agar keadilan bagi penyintas dapat terwujud. Namun terwujudnya keadilan bukanlah wewenang dari KKR.

Responden AW menilai bahwa penting untuk mengelompokkan penyintas konflik agar dapat saling menguatkan. Pengelompokan penyintas konflik penting untuk dilakukan karena dapat menyeimbangkan kondisi psikologis penyintas, memperkuat ikatan kekeluargaan antar penyintas, serta memperbaiki kondisi ekonomi penyintas sehingga penyintas dapat lebih baik dalam interaksi sosial antar sesama (Antic-Stauber, 2017). Selanjutnya, responden SFFR menyampaikan bahwa perwujudan keadilan transisi melalui pengungkapan kebenaran merupakan tanggung jawab seluruh komponen masyarakat. Gasparelli, dkk. (2016) menyampaikan bahwa seluruh komponen masyarakat, seperti pemerintah, instansi, dan penyintas harus memiliki komitmen untuk 
bertanggung jawab atas tercapainya keadilan transisi melalui pengungkapan kebenaran.

Tidak hanya itu, responden SFFR juga mengharapkan agar pemerintah Aceh mengambil kebijakan untuk membuka lapangan pekerjaan atau memberikan modal usaha bagi penyintas konflik Aceh. Hambatan terbesar dalam peningkatan efektivitas pengungkapan kebenaran ialah tidak adanya dukungan dari pihak pemerintah sedangkan keberhasilan pengungkapan kebenaran bergantung pada kebijakan pemerintah dalam menangani kondisi ekonomi (Papi, 2015). Oleh karena itu, kebijakan dari pemerintah merupakan hal yang penting untuk memastikan keberhasilan dari pengungkapan kebenaran. Twose dan Mahoney (2015) juga menyatakan bahwa persetujuan dari masyarakat serta dukungan pemerintah terhadap strategi rekonsiliasi diawali dengan pengungkapan kebenaran.

Kendala yang dihadapi dalam pengungkapan kebenaran menurut responden AW ialah kurangnya fasilitas penunjang pelaksanaan. Responden SFFR mengungkapkan bahwa hambatan lainnya yang dihadapi dalam pelaksanaan pengungkapan kebenaran ialah pembatasan dalam hal pengajuan anggaran yang berpengaruh pada hambatan dalam pemberian dukungan psikososial. Hal tersebut sesuai dengan penelitian Rokhideh (2017) yang menyampaikan bahwa kendala pendanaan menjadi salah satu penyebab terhambatnya pemberian dukungan psikososial.

Responden FH menilai bahwa pengungkapan kebenaran sesuai dengan nilai yang dianut masyarakat Aceh yang mayoritas beragama Islam dan meyakini bahwa kesalahan harus diungkapkan. Selain itu, menurut responden $\mathrm{FH}$ pengungkapan kebenaran merupakan kegiatan yang sangat ekspresif dan sesuai dengan karakter masyarakat Aceh itu sendiri yang ekspresif. Selanjutnya, responden AW menanggapi bahwa pengungkapan kebenaran dinilai sesuai dengan budaya dan moral masyarakat Aceh yang berhati lapang dan ikhlas.

Millar (2015) menyatakan bahwa pemahaman terhadap konteks budaya lokal merupakan hal yang penting karena pengungkapan kebenaran akan diterima dengan baik oleh masyarakat setempat apabila dalam pengimplementasiannya tidak bertolak belakang dengan budaya setempat. Guthrey (2016) dalam penelitiannya menyatakan bahwa pengungkapan kebenaran yang menyimpang dengan norma dan budaya lokal dapat menyebabkan penyintas tertekan dan khawatir, bahkan mengalami retraumatisasi.

Pengungkapan kebenaran juga harus disesuaikan dengan persepsi budaya lokal tentang katarsis maupun pemulihan, karena tidak semua budaya sesuai dengan pengungkapan kebenaran sebagai media katarsis dan pemulihan sosial (Lawry-White, 2015). Berdasarkan pernyataan tersebut, maka penyesuaian antar pengungkapan kebenaran dengan budaya setempat sangat penting untuk diperhatikan sehingga upaya pemulihan sosial dan rekonsiliasi dapat diwujudkan melalui pengungkapan kebenaran.

Responden AD memiliki pandangan yang berbeda yang menyatakan bahwa kesesuaian pengungkapan kebenaran dengan masyarakat Aceh tidak dapat digeneralisasikan karena setiap masyarakat memiliki karakter yang berbeda. Hass (2017) dalam penelitiannya menyebutkan bahwa langkah yang ditempuh untuk memulihkan trauma penyintas konflik tidak dapat digeneralisasikan. Berdasarkan pernyataan tersebut, maka dapat dikatakan bahwa pengungkapan kebenaran tidak dapat dinyatakan tepat bagi keseluruhan masyarakat Aceh, karena setiap individu melalui proses yang berbeda antar satu sama lain.

Selanjutnya responden AD menanggapi bahwa konflik Aceh berdampak pada kehidupan sosial masyarakat Aceh yang berupa kurangnya rasa percaya antar sesama sehingga pengungkapan kebenaran dinilai tepat sebagai pemulihan sosial paska konflik. Davis, Nsengiyumva, dan Hyslop (2019) menyampaikan bahwa paparan konflik dalam jangka waktu yang lama akan berdampak pada penurunan tingkat kepercayaan baik secara vertikal yaitu masyarakat dengan pemerintah maupun horizontal yaitu antar masyarakat. Pengungkapan kebenaran dikatakan dapat meningkatkan kepercayaan dan toleransi sosial penyintas konflik (Davis, Nsengiyumva, \& Hyslop, 2019). Selanjutnya, Antic-Stauber (2017) juga menyampaikan bahwa pengungkapan kebenaran dapat 
membantu memulihkan kepercayaan penyintas paska konflik. Peningkatan kepercayaan berdampak positif bagi penyintas konflik yang berupa kemampuan untuk mengatur diri dan berpartisipasi dalam kehidupan sosial (Davis, Nsengiyumva, \& Hyslop, 2019).

Seluruh responden menyampaikan bahwa konflik Aceh memberikan dampak sosial bagi kehidupan masyarakat. Responden SFFR menyampaikan bahwa masyarakat mengalami trauma, rasa takut berlebih terhadap aparat hingga menangis bahkan mengalami sakit fisik. Penanganan dampak psikologis seperti trauma dan rasa takut berlebih, serta sakit fisik yang dialami penyintas akibat konflik dapat dilakukan dengan mengintegrasikan kesehatan mental dan dukungan psikososial (Hertog, 2017). Tankink dan Bubenzer (2017) menyampaikan bahwa intervensi terhadap permasalahan kesehatan merupakan langkah pertama yang harus ditempuh untuk menangani permasalahan sosial dan politik dalam suatu komunitas.

Responden AW menilai bahwa konflik menyebabkan akumulasi kemarahan masyarakat dan berdampak pada kehidupan sosial. Pengalaman traumatis yang dialami akibat konflik memberikan dampak yang signifikan bagi kehidupan sosial masyarakat (Salih \& Samarasinghe, 2017). Oleh karena itu, maka pemulihan psikologis dilakukan melalui pengungkapan kebenaran untuk memberikan perbaikan dalam bidang kehidupan sosial (Hass, 2017). Adapun pemulihan psikologis yang diberikan perlu disesuaikan dengan kontur kehidupan penyintas agar kapasitas layanan kesehatan mental dapat dikembangkan dengan tepat (Rokhideh, 2017).

Seluruh responden mengalami dampak psikologis dan fisik akibat keikutsertaannya dalam pengungkapan kebenaran. Dampak yang dialami tidak terlepas dari pengalaman masa lalu statement takers yang pernah mengalami konflik hingga pada akhirnya berhasil menjadi penyintas. Responden AW merasa jenuh mendengar kesaksian penyintas konflik dan mengalami emosi marah sebagai bentuk pengalihan dari kesedihan saat mendengar pernyataan penyintas. Selanjutnya, responden AD mengalami reaksi emosional yaitu merasa sedih saat pengungkapan kebenaran.
Responden FH merasa sedih namun kesedihan tersebut dipastikan tidak mengurangi kualitas hidupnya. Adapun responden SFFR mengalami dampak fisik dan psikologis yang berupa sakit kepala karena kelelahan, trauma, memimpikan pengalaman penyintas, takut terhadap gelap dan hantu, serta terbayang seakan ada mayat.

statement takers memiliki peluang untuk mempromosikan pengungkapan kebenaran dan pemulihan psikologis bagi penyintas melalui advokasi kepada pihak berwenang (Havig \& Byers, 2019). Meskipun begitu, statement takers memiliki risiko yang akan berdampak pada fisik dan psikologis (Edlmann, 2017). Tugas statement takers yang harus mendengar, menulis, dan membaca ulang laporan dari pengungkapan kebenaran merupakan hal yang berat sehingga menjadi beban psikologis bagi statement takers (Gasparelli, dkk., 2016). Namun, untuk menjalankan tugasnya, statement takers terlebih dahulu diberikan pembekalan terkait Standar Operasional Prosedur (SOP) pengungkapan kebenaran. Oleh karena itu, ketersediaan sumber daya manusia untuk mengikuti SOP yang telah ditetapkan serta mengerjakan tugas yang penuh tekanan sangatlah terbatas (Tankink, Bubenzer, \& Walt, 2017). Hal tersebut menuntut komitmen dan konsistensi statement takers agar ikut serta secara intensif dalam pengungkapan kebenaran untuk mewujudkan pemberdayaan diri dan pemulihan psikologis (Havig \& Byers, 2019).

Adapun menurut responden $\mathrm{FH}$ tujuan lainnya dari pengungkapan kebenaran ialah agar negara memiliki dokumen resmi terkait konflik. Sebagaimana yang dinyatakan oleh Appleby dan Davis (2018) bahwa pengungkapan kebenaran dilakukan agar data terkait konflik dapat diarsipkan sebagai dokumen resmi terkait konflik, dan kemudian dipublikasikan agar masyarakat mengetahui sejarah konflik.

Menurut responden AW, pengungkapan kebenaran dianggap dapat mengungkit kembali pengalaman penyintas terkait konflik. Lawry-White (2015) menyebutkan bahwa pengungkapan kebenaran dapat mengingatkan penyintas terhadap pengalaman konflik, namun dalam penelitian yang dilakukannya penyintas mengakui bahwa hal tersebut juga menjadi media pemulihan emosional. Ingabire, dkk (2017) 
juga menyampaikan bahwa salah satu langkah yang harus ditempuh untuk mencapai pemulihan emosional dan rekonsiliasi ialah pengungkapan kebenaran. Selanjutnya, responden AW menegaskan bahwa pengungkapan kebenaran bermanfaat terutama sebagai langkah awal untuk menemukan kebenaran konflik yang kemudian diingat sebagai sejarah agar konflik serupa tidak terulang lagi. Pengungkapan kebenaran di Afrika Selatan kemudian dicatat dalam sejarah melalui pembangunan museum yang menceritakan tentang peristiwa konflik mengenai pembantaian, perampasan, dan perlawanan (Appleby \& Davis, 2018).

Pengungkapan kebenaran akan tetap dilaksanakan meskipun dalam beberapa kondisi akan memberikan dampak negatif baik bagi statement takers maupun penyintas konflik. Namun, hal yang dapat dilakukan untuk mengantisipasi dampak negatif dari pengungkapan kebenaran menurut responden $\mathrm{AD}$ ialah dengan memberikan layanan psikologis dan memonitor kondisi penyintas paska pengungkapan kebenaran. Responden FH mengharapkan agar adanya kerja sama dengan pihak yang fokus bergerak dalam pemulihan psikologis. Dengan begitu, maka pengungkapan kebenaran dapat terlaksana serta membantu pengembalian harkat dan martabat penyintas konflik sebagaimana yang disampaikan oleh responden AW.

Beberapa dampak negatif yang dialami penyintas akibat konflik yaitu kemiskinan, penurunan kesahatan fisik dan mental, serta tingkat pendidikan rendah (Davis, Nsengiyumva, \& Hyslop, 2019). Oleh karena itu, diperlukan adanya keterlibatan penyintas secara langsung dalam pengungkapan untuk menangani dampak negatif melalui pemulihan psikologis (Mawhinney, 2015). Keterlibatan penyintas konflik dalam pengungkapan kebenaran akan meningkat apabila peningkatan kesadaran penyintas akan dampak psikologis yang dialami juga meningkat (Mansfield, 2017). Dengan begitu, promosi terhadap penyintas konflik harus dilakukan untuk mencapai transformasi paska konflik sehingga penyintas berdaya, sehat secara fisik dan emosional, produktif, terlibat secara sosial, dan sejahtera (Tankink, Bubenzer, \& Walt, 2017).
Berdasarkan pembuktian yang dilakukan secara empiris, ditemukan bahwa pemulihan trauma melalui pengungkapan kebenaran merupakan aspek terpenting dalam terwujudnya perdamaian dan rekonsiliasi di Rwanda (Davis, Nsengiyumva, \& Hyslop, 2019). Pengungkapan kebenaran juga memfasilitasi penyintas untuk dapat berdamai dengan ingatan terkait pelanggaran HAM yang pernah dialami pada masa konflik, setidaknya hal tersebut menjadi langkah awal bagi pemenuhan keadilan transisi penyintas (Tankink \& Bubenzer, 2017).

Pengungkapan kebenaran konflik Aceh merupakan kegiatan yang sangat tepat untuk dilaksanakan demi melestarikan perdamaian Aceh serta menuntaskan perihal keadilan transisi penyintas yang belum selesai. Namun, pelaksanaan pengungkapan kebenaran membutuhkan dukungan dari berbagai pihak berwenang agar dapat terlaksana dengan baik dan mencapai tujuan yaitu rekonsiliasi. Pengungkapan kebenaran juga memberikan dampak terhadap berbagai sektor kehidupan masyarakat. Oleh karena itu, demi menjamin keamanan dan kenyamanan penyintas serta masyarakat umum, maka diperlukan adanya kerja sama dengan pihak pemberian layanan psikologis, serta memberikan dukungan psikososial yang bertujuan untuk pemulihan penyintas konflik Aceh.

\section{Kesimpulan}

Pelaksanaan pengungkapan kebenaran konflik Aceh memiliki kendala yang terdiri dari kendala kelembagaan, kendala internal, dan kendala eksternal. Kendala lainnya yang dihadapi ialah rendahnya pengetahuan penyintas dan masyarakat terhadap pengungkapan kebenaran konflik. Meskipun begitu, pengungkapan kebenaran konflik sesuai dengan nilai moral dan budaya masyarakat Aceh walaupun kesesuaian antar pengungkapan kebenaran dengan masyarakat tidak dapat digeneralisasikan karena setiap masyarakat memiliki karakter yang berbeda. Konflik Aceh memberikan dampak yang signifikan terhadap kehidupan sosial dan psikologis penyintas. Oleh karena itu, pengungkapan kebenaran konflik Aceh dinilai tepat sebagai langkah awal untuk pemulihan sosial dan psikologis, serta memberikan keadilan transisi bagi penyintas 
konflik Aceh. Selanjutnya, pengungkapan kebenaran konflik Aceh dapat menjadi dokumen sejarah yang bermanfaat bagi generasi muda dan menjadi tindakan preventif agar konflik tidak terulang kembali. Tidak hanya itu, statement takers mengalami reaksi emosional, terbeban secara moral, serta mengalami dampak fisik dan psikologis paska pengungkapan kebenaran konflik Aceh.

\section{Referensi}

Akbar, K. 2017. Politik hukum pembentukankomisi kebenaran dan rekonsiliasi Aceh. Lex Renaissance, 2(2), 195-212. [Internet]. Diakses pada 25Maret 2019. Tersedia pada https://journal.uii.ac.id/LexRenaissance /article/view/12027

Allport, F. H. 1955. Theories of perception and the concept of structure: A review andcritical analysis with and introduction to a dynamic structural theory of behavior.[Internet]. Diakses pada 17 Maret 2019 Tersedia pada https://archive.org/details/theoriesofpe rcep00allp

Antic-Stauber, B. 2017. Snaga Zene: A model for healing trauma beyon psychological treatment. Intervention Journal, 15, 293 301. [Internet]. Diakses pada 17 Maret 2019. Tersedia pada http://doi:10.1097/WTF.000000000000 0162

Appleby, G., \& Davis, M. 2018. The Uluru statement and the promises of truth. Australian Historical Studies, 49, 501509. [Internet]. Diakses pada 16 April 2020. Tersedia pada http://doi:10. 1080/1031461X.2018. 1523838

CNN Indonesia (2017, 25 Oktober) Satutahun berdiri, KKR Aceh belum terima dukungan pemerintah. CNN Indonesia. Diakses dari https://www.cnnindonesia.com/nasinal /2017102422150112250837/satutahun -berdiri-kkr-aceh-

belumterimadukungan-pemerintah

Davis, A., Nsengiyumva, C., \& Hyslop, D.2019. Healing trauma and building trust and tolerance in Rwanda. International Organization for Peacebuilding, 4, 1-54. [Internet]. Diakses pada 25 April 2020. Tersedia pada https://www.interpeace.org/wpcontent
/uloads/2019/04/TraumaustTolerancea ndPeaceactivismWeb.pdf

Edlmann, T. 2017. A reflection on narrative based historical memory work in peacebuilding processes. Intervention ournal, 15, 230-240. [Internet]. Diakses pada 24 Maret 2020. Tersedia pada http://doi:10.1097/WTF.000000000001 68

Farid, H., \& Simarmata, R. 2004. Demi kebenaran pemetaan upaya-upaya pencarian keadilan dalam masa transisi di Indonesia. Jakarta: ELSAM (Lembaga Studi dan Advokasi Masyarakat). [Internet]. Diakses pada 24 Maret 2020. Tersedia pada http://referensi.elsam.or.id/wpcontent/ uploads/2014/09/11.DemiKebenaran_P emetaanUpayaUpayaPencarianKeadilan DalamMasaTransisi-di-Indoenesia.pdf

Gasparelli, K., Crowley, H., Fricke, M.,McKenzie, B., Oosman, S., \& NixonS. A. 2016. Mobilizing reconciliation: Implications of the truth and reconciliation commission report for physiotherapy in Canada. Canada Physiotherapy Association, 68, 211-212. [Internet]. Diakses pada 22 Juni 2019. Tersedia pada http://doi:10.3138/ptc.68.3.GEE

Goldstein, E. B. 2013. Sensation and perception (9th ed.). USA: Wardsworth Cengage Learning. [Internet]. Diakses pada 23 April 2020. Tersedia pada http://dl.icdst.org/pdfs/files/613782cdf 896905bb1706aecb765

Gonzalez, E., \& Varney, H. 2013. Truth seeking: Elements of creating an effective truth commission. New York: International Center for Transitional Justice. [Internet]. Diakses pada 13 Januari 2020. Diakses dari https://www.ictj.org/sites/default/files /ITJ-BookTruthSeeking2013English.pdf

Guthrey, H. L. 2016. Expectations and promises in the quest for truth: Examining victms' perceptions of truth commission participation in Solomon Islands and Timor-Leste. Peace and Conflict: Journal of Peace Psychology, 22, 306-317. [Internet]. Diakses pada 13 Januari 2020. Tersedia pada http://doi:10.1037/pac0000198 
Hamid, A. F. 2019. Jalan damai nanggroe endatu: Catatan seorang wakil rakyat Aceh. Banda Aceh: Bandar Publishing.

Hass, K. L. 2017. Exploring the link between trauma and truth in post conflict societies: Comparing post conflict Northern Ireland and post apartheid South Africa. Intervention Journal, 15,

54-263. [Internet]. Diakses pada13 Januari 2020. Tersedia pada http://doi:10.1097/WTF.000000000001 66

Havig, K., \& Byers, L. 2019. Truth, reconciliation, and social work: Acritical pathway to social justice and antioppressive practice. Journal of Social Work Values and Ethics, 16(2), 70-80. [Internet]. Diakses pada 20 Maret 2020. Tersedia

pada https://jswve.org/download/fall_201vol ume_16_no2/articles/70Truthreconciliat ionsocialwork162Fall2019.pdf

Hayner, P. B. 2011. Unspeakable truths: Transitional justice and the challenge of truth commissions (2nd ed.). New York: Routledge. [Internet]. Diakses pada 23 Desember 2019. Tersedia pada https://www.mcgill.ca/isid/files/isid/pr iscilla_b._haynerunspeakabletrutstransiti bokzz.org.pdf

Hertog, K. 2017. The intrinsic interlinkage between peacebuilding and mental health and psychosocial support: The international association for human values model of integrated psychosocial peacebuilding. Journal Intervention, 15, 278-292. [Internet]. Diakses pada 20 Januari 2020. Tersedia pada http://doi:10.1097/WTF.000000000000 167

Ingabire, C. M., Kagoyire, G., Karangwa, D., Ingabire, N., Habarugira, N., Jansen, A., \& Richters, A. 2017. Trauma informed restorative justice through community based sociotherapy in Rwanda. Intervention Journal, 15, 241-253. [Internet]. Diakses pada 19 Januari 2020. Tersedia pada http://doi:10.1097/WTF.000000000001 63

Kemendagri pertanyakan KKR Aceh. $B B C$ News. 2013. [Internet]. Diakses pada tanggal 13 Oktober 2019. Tersedia pada https://www.bbc.com/indo nesia/berit_indonesia/2013/12/13122k emendagripertanyakankkraceh

KKR Aceh ambil kesaksian korban pelanggaran HAM, KontraS beri data. Kanal Aceh. 2017 [Internet]. Diakses pada 23 Februari 2020. Tersedia pada https://www.kanalaceh.com/2017/11/ 30/kkracehambilkesaksiankorbanpelang garanhmkontrasberidata/

KKR Aceh mulai mendengarkan kesaksian korban dugaan pelanggaran HAM. 2018. $B B C$ News. [Internet]. Diakses pada 14 Juni 2019. Tersedia pada https://www.bbc.com/indonesia/indon esia46396048

Komisi Kebenaran dan Rekonsiliasi Aceh. Pernyataan sikap rapat dengar kesaksian KKR Aceh tahun 2019 penghilangan orang: Kembalikan mereka, jangan terulang. Komisi Kebenaran dan Rekonsiliasi Aceh. $2019 . \quad$ [Internet]. Diakses pada 25 Januari 2020. Tersedia pada

https://kkr.acehprov.go.id/pernyataansi krapatdengarkesaksiankkracehtahun20 19penghilanganorangkembalikanmerek ajanganterulang/

Lawry-White, M. 2015. The reparative effect of truth seeking in transitional justice. International and Comparative Law Quarterly, 64, 141-177. [Internet]. Diakses pada 22 Januari 2020. Tersedia pada http://doi:10.1017/ S0020589314000645

Leebaw, B. A. 2003. Legitimation or judgment? South Africa's restorative approach to transitional justice. Polity, 36(1), 23-51. [Internet]. Diakses pada 21 Januari 2020. Tersedia pada http://www.ictj.org/

Lorey, D. E., \& Beezley, W. H. 2002. Genocide, collective violence, and popular memory: The politics of remembrance in the twentieth century. United States: Rowman \& Littlefield. [Internet]. Diakses pada 16 Januari 2020. Tersedia pada https://journals.sagepub.com/doi/10.1/ 0162243916658708

Mansfield, K. 2017. Strategies for trauma awareness and resilience programme: Experiental education towards resilience and trauma informed people and practice. Intervention Journal, 15, 264277. [Internet]. Diakses pada 23 Maret 2020. Tersedia pada 
http://doi:10.1097/WTF.000000000000 0164

Mawhinney, E. B. 2015. Restoring just ice:Lessons from truth and reconciliation in South Africa and Rwanda. Journal of Public Law and Policy, 36(2), 21- 52. [Internet]. Diakses pada tanggal 22 Januari 2020. Tersedia pada http://digitalcommons.hamline.edu/jplp /vol36/iss $2 / 2$

Miles M. B., \& Huberman, A. M., \& Saldana, J. 2014. Qualitative Data Analysis: A Methods Source Book (3nd ed.). United States: Sage Publication.

Millar, G. 2015. Performative memory and revictimization: Truth-telling and provocation in Sierra Leone. Memory Studies, 8, 242-254. [Internet]. Diakses pada 21 Januari 2020. Tersedia pada http://doi:10.1177/175069801351913

Minow, M. 1998. Between vengeance and forgiveness: Facing history after genocide and mass violence. Boston, MA: Beacon Press Books. [Internet]. Diakses pada 22 Januari 2020. Tersedia pada https://dash.harvard.edu/bitstream/ha $\mathrm{ndl} / 1$

Mutua, M. 2015. What is the future of transitional justice? International Journal of Transitional Justice, 9, 19.

[Internet]. Diakses pada 21 Januari 2020. Tersedia pada http://doi:10.1093/ijtj/iju032

Papi, K. E. 2015. The role of transitional justice processes in building peace in Latin America. E International Relations, 1-12. [Internet] Diakses pada 18 Maret 2020. Tersedia pada https://www.eir.info/2015/01/23/ther oleoftransitionaljusticeprocessesinbuild ngpeaceinlatinamerica/

Rokhideh, M. 2017. Peacebuilding and psychosocial intervention: The critical need to address everydaypost conflict experiencies in Northern Uganda. Intervention Journal, 15, 215-229. [Internet]. Diakses pada 13 Maret 2020. Tersedia pada http://doi:10.1097/WTF.000000000000 161

Salih M., \& Samarasinghe, G. 2017. Families of the missing in Sri Lanka: Psychosocial considerations in transitional justice mechanism. International Review of The Red Cross, 99, 497-517. [Internet].
Diakses pada 22 Maret 2020. Tersedia pada

http://doi:10.1017/S181638311800051 6

Tankink, M., \& Bubenzer, F. 2017. Building sustainable peace through an integrated approach to peacebuilding and mental health and psychosocial support: A literature review. Intervention Journal, 15, 199-214. [Internet]. Diakses pada 22 Maret 2020. Tersedia pada http://doi:10.1097/WTF.000000000000 0165

Tankink, M., \& Bubenzer, F. 2017. Introduction to special issue: Linking mental health and psychosocial support to peacebuilding in a integrated way. Intervention Journal, 15, 192-198. [Internet]. Diakses pada 23 Maret 2020. Tersedia pada http://doi:10.1097/WTF.000000000000 160

Tankink, M., Bubenzer, F., \& Walt, S. V. D. 2017. Achieving sustainable peace through an integrated approach to peacebuilding and mental health and psychosocial support: A review of current theory and practice. Institute for Justice and Reconciliation and the War Trauma Foundation. [Internet]. Diakses pada 22 Maret 2020. Tersedia pada https://www.ijr.org.za/portfolioitems/a chievingsustainablepeacethroughaninteg ratedapproachtopeacebuildingandmenta lhealthandpsychosocialsupport/

Tepperman, J. D. 2002. Truth and concesquences. Foreign Affairs, 81, 12145. [Internet]. Diakses pada 22 Maret 2020.

Tersedia padahttp://doi:10.1177/001083671245 423

TRC leaves deep scars on staff. Mail \& Guardian. 1997. [Internet]. Diakses pada 12 Maret 2020. Tersedia pada https://mg.co.za/article/19971212trcle aves-deep scars on-staff

Twose, G., \& Mahoney, C. O. (2015). The trouble with truth-telling: Preliminary reflections on truth and justice in postwar Liberia. Peace and Conflict Studies, 22(2), 85-112. Diakses dari http://nsuworks.nova.edu/pcs/vol22/is $2 / 1$

Zairi, M. B. Selama tiga tahun, KKR Aceh sudah periksa 3.040 korban konflik. 
Serambi Indonesia. 2019. [Internet]. Diakses pada 21 Januari 2020. Tersedia pada

https://aceh.tribunnews.com/2019/10/ 24selamatigatahunkkracehsudahperiksa 3040korbankonflik 